\title{
Preparation of Fermentation Medium of Rhizobium Meliloti Using Leaching Liquor of Corn Stalk
}

\author{
Shuqin Zhang \\ Institute of Soil and Environment Bioremediation in \\ Karst habitats \\ Guizhou Normal College \\ Guiyang, China \\ e-mail: smartclover@foxmail.com
}

\author{
Jianfeng Li \\ Key Laboratory for Grassland Ecosystem of Ministry of \\ Education \\ Gansu Agricultural University \\ Lanzhou, China \\ e-mail: alexclover@foxmail.com
}

\author{
Jianxiong $\mathrm{Du}^{*}$ \\ Guizhou University of Finance and Economics \\ Guiyang, China \\ e-mail: djx7401@yahoo.com.cn
}

\begin{abstract}
In order to explore Rhizobium medium production using leaching liquor of green corn straw. Corn stalk powder extract solutions (CSE) are obtained and suitable carbon sources (glucose) were supplemented as liquid and solid Rhizobium medium. Compared with the yeast extract mannitol (YEM) medium, Rhizobium meliloti GN5 and Rhizobium meliloti 3436 are inoculated in two medium and viable cells after $30 \mathrm{~h}$ fermentation were tested. Results show that nitrogen and carbon source in CSE medium can be utilized well by Rhizobium cells. Effect of CES-2 (ratio of green stalk powder and water is 1:50) of Rhizobium fermentation is better than that of YEM when additional glucose were supplemented. The growth of two Rhizobium colonies in CES-3 (the ratio of green corn stalk powder and water is 1:100) agar plate similar or big than that of YEM agar plate. The results suggest that suitable ratio green corn stalk extraction liquid with supplementation of additional carbon source can be used to product cheap and high quality medium for Rhizobium plate culture and fermentation.
\end{abstract}

Keywords- Rhizobium; Medium; Corn stalk; inoculate; leaching liquor

\section{INTRODUCTION}

During the legume crops production, the use of Rhizobium inoculants has become the recommended process in America, Brazil and other countries [1]. The Rhizobium inoculants are designed as a protective environment for Rhizobium [2]. Many researchers and manufacturers recognize that the high quality Rhizobium inoculants depend on many factors, including low cost, containing enough viable cells, etc [3]. Therefore, Reduce cost and being suitable for the strains growth and survival in medium is one of the key technologies for inoculants production [4].

During the development of the Rhizobium inoculants, the method for using chemical medium formula under high cost. Improving quality of medium, reduce costs and contamination [5]. Corn stalk yield of global corn is huge mainly composed of lignin and hemi lignin, green corn stalk contains soluble sugar, protein, nucleic acid, soluble nitrogen, phosphorus, other nutrients and trace elements [6]. In this feasibility study, the corn stalk used as raw materials containing nutrition source of the Rhizobium mediums, and discuss the advantages compared with traditional culture medium such as yeast mannitol medium.

\section{MATERIALS AND METHODS}

\section{A. Materials and Medium}

Rhizobium strains: Rhizobium meliloti 3436 and Rhizobium meliloti GN5 of alfalfa Rhizobium had been identified Rhizobium meliloti by Chinese scientists [General Microbiological Culture Collection Center (CGMCC)], and provided key laboratory of Grassland ecosystem of Ministry of Education.

The Preparation for leaching liquor of green corn stalk: Green corn straw was obtained from the experimental field of corn on school farm, after corn seeds were harvested as soon as possible. Top 3/4 straw and all leaves was taken and cut into about $20 \mathrm{~cm}$ short, dried $48 \mathrm{~h}$ at $110{ }^{\circ} \mathrm{C}$, crushed by using small mill and sieved with 2 mm screen. $20 \mathrm{~g}$ powder was respectively taken out and respectively added into $0.5,1,2$ and 4 liter distilled water, extracted $4 \mathrm{~h}$ at $80^{\circ} \mathrm{C}$. Extract liquid was filtered with qualitative filter paper 3 times, adjusted $\mathrm{pH}$ value to 7.0 
\pm 0.1 , and prepared into straw powder extract liquid of the weight ratio of $1: 25,1: 50,1: 100$ and $1: 200$ of dry stalk powder. Extract liquid of all gradients was dumped into Erlenmeyer flask and autoclaved $121^{\circ} \mathrm{C}$ for $25 \mathrm{~min}$. For convenience of description, green corn stalk powder liquid of $1: 25,1: 50,1: 100$ and 1:200 were named as CSE1, CSE-2, CSE-3, CSE-4, respectively [7].

\section{B. The incubation experiment of CSE series liquid as culture medium}

Take $200 \mathrm{ml}$ liquid inoculate 50 $\mathrm{\mu l}$ Rhizobium GN5 suspension $\left(10^{9}\right.$ cells $\left.^{-1}\right), 120 \mathrm{rpm}, 28^{\circ} \mathrm{C}$ for $30 \mathrm{~h}, 4$ replicates per treatment. 8h later, OD600nm absorbance value was measured per two hours. Adjusting spectrophotometer to zero corresponding to YEM medium and CSE liquid without inoculate.

YEM medium preparation: yeast powder $2 \mathrm{gL}^{-1}$, $\left.\mathrm{FeSO}_{4} 0.005 \mathrm{gL}^{-1}, \mathrm{NH}_{4}\right)_{2} \mathrm{SO}_{4} 0.2 \mathrm{gL}^{-1}, \mathrm{MgSO}_{4} \cdot 7 \mathrm{H}_{2} \mathrm{O} 0.1$ $\mathrm{gL}^{-1}, \mathrm{KCl} 0.2 \mathrm{gLL}^{-1}, \mathrm{MnSO}_{4} 0.02 \mathrm{gL}^{-1}, \mathrm{NaCl} 0.36 \mathrm{gL}^{-1}$, $\mathrm{K}_{2} \mathrm{HPO}_{4} 0.5 \mathrm{~g} \cdot \mathrm{L}^{-1}$; YMA solid medium are YEM plus 15 $\mathrm{g} \mathrm{L}^{-1}$ agar powder.

In order to understand carbon source and phosphorus nutrition utilization rate of straw powder extract for strains, in addition to taking all different dilution CSE liquid medium and the fermentation liquid. Measure the soluble sugar change in each dilution CSE before and after inoculation [8]. Soluble nitrogen of the CSE series of extract liquid was determined by Li's method [7].

The different dilution CSE liquid was added with 10 $\mathrm{g}^{\mathrm{m} l^{-1}}$ glucose and $15 \mathrm{gl}^{-1}$ agar, Rhizobium meliloti GN5, and Rhizobium meliloti 3436 were inoculated in CSE solid agar plate, the YMA medium as control, 4 replicates per treatment, and cultured at $28^{\circ} \mathrm{C}$ for $72 \mathrm{~h}$ to determine the colony diameter with vernier caliper.

The strain growth generation time, viable cells of bacteria in CSE liquid, and colony diameter size formed on CSE agar plates was used to evaluate the feasibility of straw powder extract liquid as Rhizobium medium.

\section{Data Procession and Analysis}

The data was presented as means \pm SE and differences of variables between treatments were compared using one way ANOVA followed by Duncan's test. The statistical software SPSS 16.0 was used.

\section{RESUlts AND ANALYSIS}

\section{A. The Utilization Ability of Different Carbon Source for Rhizobium}

Fig.1 shows two Rhizobium strains can utilize all carbon source by tested, there is a great difference in utilization ability of different carbon source for two strains, but there is lower utilization ability of fructose for two strains. 3436 grow best with glucose as carbon source, viable cells in medium with glucose as carbon source is higher $113.3 \%$ and $37.7 \%$ than that of fructose and lactose as sole carbon source, significantly $(\mathrm{P}<0.05)$; The Rhizobium GN5 grow best with mannitol as sole carbon source, viable cells of in medium is higher $226.4 \%$ and $63.2 \%$ than that of sucrose and glucose as sole carbon source $(\mathrm{P}<0.05)$, and no significant difference between mannitol and glucose treatment. Considering the costs of carbon sources, glucose is chosen as the most suitable fermentable carbon sources for GN5 and 3436.

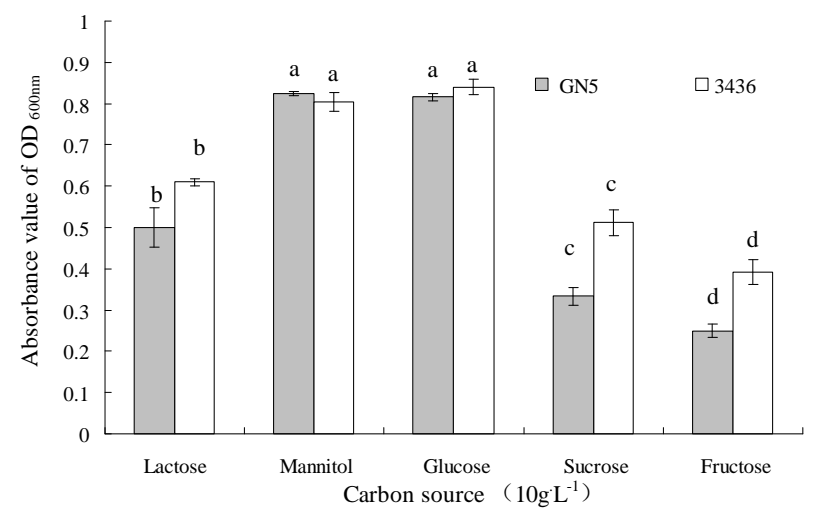

Figure 1. Utilization ability of Rhizobium meliloti GN5 and Rhizobium meliloti 3436 for carbon source in $\mathrm{N}$-free liquid medium

* Note: the different small letters mean significant difference among the different treatments $(P<0.05)$, results are means \pm SD $(n=4)$. same blew.

\section{B. The liquid and plate culture of Rhizobium strains using CSE medium}

Table 1 shows that the generation times of strain GN5 in no exotic carbon source and different concentration CSE are not consistent. The shortest generation times in CSE-2 was significant shorter $20 \%$ than that of YEM $(P<0.05)$. After 20h fermentation, viable cells of Rhizobium in CSE2 are higher $14.83 \%$ than that of YEM. This result suggested that CSE and CSE-2 could be used as Rhizobium fermentation in liquid culture medium, the fermentation effect of CSE-2 during early stage of fermentation was better than that of traditional YEM liquid medium, so it has a high application value.

TABLE I. DOUBLING TIME AND VIABLE CELLS OF RHIZOBIUM MELILOTI GN5 IN CSE MEDIUM *

\begin{tabular}{|c|c|c|c|}
\hline Medium & $\begin{array}{l}\text { Doubling time } \\
(\text { h·generation }\end{array}$ & $\begin{array}{l}\text { Viable cells after } \\
20 \mathrm{~h} \text { fermentation } \\
\left(10^{8} \mathrm{cfu} \cdot \mathrm{ml}^{-1}\right)\end{array}$ & $\begin{array}{l}\text { Viable cells after } \\
30 \mathrm{~h} \text { fermentation } \\
\left(10^{8} \mathrm{cfu} \cdot \mathrm{ml}^{-1}\right)\end{array}$ \\
\hline CSE-1 & $3.67 \pm 0.42^{b}$ & $3.78 \pm 0.09^{c}$ & $10.03 \pm 0.11^{b}$ \\
\hline CSE-2 & $2.04 \pm 0.19^{e}$ & $5.11 \pm 0.12^{\mathrm{a}}$ & $5.56 \pm 0.16^{c}$ \\
\hline CSE-3 & $2.98 \pm 0.14^{c}$ & $2.22 \pm 0.12^{\mathrm{d}}$ & $2.66 \pm 0.07^{d}$ \\
\hline CSE-4* & $14.30 \pm 0.31^{a}$ & $0.74 \pm 0.05^{\mathrm{e}}$ & $0.72 \pm 0.12^{d}$ \\
\hline $\begin{array}{l}\text { YEM } \\
\text { (CK) }\end{array}$ & $2.55 \pm 0.11^{\mathrm{d}}$ & $4.45 \pm 0.20^{b}$ & $18.32 \pm 0.60^{a}$ \\
\hline
\end{tabular}

*Different lowercases in a column indicate significant differences at 0.05 levels among different carbon source application of each strain. *8h later, viable Rhizobium cells of in CSE-4 had entered a period of growth retardation, so generation time of Rhizobium culture could not stand for doubling time at logarithmic phase

At the same time, the results show that the viable cells number of Rhizobium in CSE-1 and CSE-2 are 54.75\% and $30.35 \%$ of YEM at 30h. The reason can be explained in the change of soluble sugar content of CSE (Table 2) before and after inoculation.

After R. meliloti GN5 is inoculated and cultured for 30h, soluble sugar in series CSE liquid has been expended. Soluble sugar content in CSE-1 is $4.89 \%$ that of before 
inoculation. It is indicated that above 95\% soluble sugar in straw extract liquid can be used by Rhizobium, the exhaustion of carbon source is the major limiting factor for the strain growth in CSE liquid. Therefore, it is necessary to supply additional carbon source such as glucose.

TABLE II. THE SOLUBLE SUGAR OF CSE MEDIUM AFTER AND BEFORE INOCULATION OF GN5*

\begin{tabular}{ccc}
\hline Medium & \multicolumn{2}{c}{ Soluble sugar content in CSE medium $\left(\mathbf{m m o l}^{-\mathbf{1}}\right)$} \\
\cline { 2 - 3 } & Fresh medium & After fermentation \\
\hline CSE-1 & $6.14 \pm 0.15^{\mathrm{a}}$ & $0.30 \pm 0.03^{\mathrm{a}}$ \\
CSE-2 & $3.32 \pm 0.11^{\mathrm{b}}$ & $0.19 \pm 0.01^{\mathrm{b}}$ \\
CSE-3 & $2.03 \pm 0.08^{\mathrm{c}}$ & $0.17 \pm 0.02^{\mathrm{b}}$ \\
CSE-4 & $1.16 \pm 0.05^{\mathrm{d}}$ & $0.10 \pm 0.02^{\mathrm{c}}$ \\
\hline
\end{tabular}

- Different lowercases in a column means the significant difference between each treatment $(P<0.05)$. Same blew.

TABLE III. DIAMETER OF GN5 AND 3436 COLONIES ON CSE AND YMA PLATES AFTER $72 \mathrm{H}$ GROWTH *

\begin{tabular}{lcccc}
\hline \multicolumn{2}{c}{ Strains } & $\begin{array}{c}* \text { CSE-3 agar } \\
\text { plate }\end{array}$ & $\begin{array}{c}\text { CSE-2 agar } \\
\text { plate }\end{array}$ & YMA plate \\
\hline $\begin{array}{l}\text { Rhizobium } \\
\text { GN5 }\end{array}$ & meliloti & $6.5 \pm 0.2^{\mathrm{a}}$ & $6.9 \pm 0.3^{\mathrm{a}}$ & $6.7 \pm 0.3^{\mathrm{a}}$ \\
$\begin{array}{l}\text { Rhizobium } \\
3436\end{array}$ & meliloti & $7.1 \pm 0.3^{\mathrm{ab}}$ & $7.4 \pm 0.1^{\mathrm{a}}$ & $7.0 \pm 0.2^{\mathrm{b}}$ \\
\hline
\end{tabular}

*Note: CSE solid medium containing $10 \mathrm{~g} \cdot \mathrm{L}^{-1}$ glucose, $15 \mathrm{~g} \cdot \mathrm{L}^{-1}$ agar, $\mathrm{pH} 7.0 \pm 0.1$.

Table 3 show that Rhizobium GN5 and 3436 can grow well in CSE-2 and CSE-3, especially fastest grow in CSE2, no significant difference in diameter of 3436 and GN5 between in CSE and YMA after $72 \mathrm{~h}$ culture. The result suggest that 1:50 and 1:100 time straw extract liquid with added into glucose as supplementary carbon source has very good utilization potential to inoculants production.

\section{DisCUSSION}

The composition of carbon and nitrogen source is about $55 \%$ of the medium cost in liquid fermentation [9]. Therefore, it is crucial for production of inoculants to choose cheaper and full utilization carbon source [10]. The green corn stalk containing carbohydrate, protein, amino acids and inorganic salt, etc to fit the need of natural microbial growth, Compared with the chemical medium, green corn stalk extract liquid as medium is more economical and practical. Straw powder extract liquid after supplied carbon source could be chosen as high quality and inexpensive fermentation medium, which had the equivalent fermentation effect with YEM medium, but the costs of it was lower several times as much as that of YEM medium. Solid medium CSE-3 added into glucose and agar was also suitable for use in solid plate culture, and colony characteristics both Rhizobium meliloti 3436 and Rhizobium meliloti GN5 were not changed.

In this experiment, we also found that the content of soluble nitrogen in CSE-1, CSE-2 and CSE-3 is respectively $1421 \mathrm{mg} \cdot \mathrm{L}^{-1}, 711 \mathrm{mg} \mathrm{L}^{-1}$, and $332 \mathrm{mg} \cdot \mathrm{L}^{-1}$, the content of soluble nitrogen in CSE-1, CSE-2 and CSE-3 is equal to or higher than that of YEM medium, which suggest that the soluble nitrogen in CSE-1, CSE-2 and CSE-3 can afford the whole fermentation process of Rhizobium.

The sole carbon source test also evaluated the efficiency of different carbon source material for strains. Result shows glucose is the best carbon source in fermentation culture of Rhizobium, The result show that the performance of glucose on fermentation of Rhizobium strain is similar or better than that of mannitol (such as GN5), significantly higher than that of sucrose, fructose, and lactose $(P<0.05)$. It is consistent with previously study [12], which indicated the Rhizobium cells could utilize glucose, sucrose as carbon source, but the growth rate of parts of strains with glucose as carbon source was best than that of other carbon source. The price of glucose is less than $35 \%$ that of mannitol [7], so it is the most suitable carbon source for fermentation culture of Rhizobium.

\section{CONCLUSIONS}

The growth generation time of strain GN5 in CSE-2 is significant shorter than that of YEM $(P<0.05)$, the carbon source material in CSE-2 can be utilized very well. Compared with the high cost of chemicals medium, the stalk extract liquid are more economical and practical. But carbon source of CSE-2 cannot afford the fermentation process, after carbon source material is supplied Straw powder extract liquid after supplied carbon source can be chosen as high quality and inexpensive fermentation medium. CSE-3 with additional glucose and agar is also suitable for use in solid plate culture for Rhizobium. The generation time of strain GN5 in CES-2 is shortened compared with YEM, nitrogen and phosphorus nutrition can be used well by Rhizobium. The effect of CSE-3 on Rhizobium colonies on agar plates are equivalent or better than that of YEM medium, which can be chose as high efficiency and inexpensive solid fermentation medium for Rhizobium.

\section{ACKNOWLEDGMENT}

This work was financially supported by National Natural Science Foundation of China (NSFC) (31300389), The Natural Science Foundation of Guizhou Province (J[2014]2136) and the Ph.D. research project of Guizhou Normal College (13BS019).

\section{REFERENCES}

[1] N. Z. Lupwayi, G. W. Clayton and W. A. Rice. "Rhizobial inoculants for legume crops,” Journal of Crop Improvement, vol. 15, Feb. 2006, pp. 289-321.

[2] D. N. Rodriguez-Navarro, F. Temprano, and R. Orive. "Survival of Rhizobium sp. (Hedysarum coronarium L.) on peat-based inoculants and inoculated seeds," Soil Biology and Biochemistry, vol. 23, 1991, pp. 375-379.

[3] L. Herrmann and D. Lesueur, "Challenges of formulation and quality of biofertilizers for successful inoculation" Applied Microbiology and Biotechnology, vol. 97, Otc. 2013, pp. 88598873.

[4] M. Hungria, M. F. Loureiro, I. C. Mendes, R. J. Campo, and P. H. Graham, "Inoculant preparation, production and application," 
Nitrogen Fixation Origins Applications and Research Progress, pp 223-253, 2006

[5] N.Z. lupwayi, P.E. Olsen, E.S. Sande, H. H. Keyser, M. M. Collins, P. W. Singleton, W. A. Rice WA, "Inoculant quality and its evaluation,” Field Crops Research, vol. 65, pp. 259-270, 2000.

[6] F. Masoero, F. Rossi, and A. M. Pulimeno, "Chemical composition and in vitro digestibility of stalks, leaves and cobs of four corn hybrids at different phenological stages,” Italian Journal of Animal Science, vol. 5, March 2006, pp. 215-227.

[7] J. F. Li, Isolation and Screening for Phosphate Solubilizing Rhizobium and key manufacturing technology of their Anticontamination Inoculants, PhD degree thesis: Gansu Agricultural University, July 2012, pp. 24-30.

[8] R. Li, J. J. Volenec, B. C. Joern, and S. M. Cunningham, “Seasonal changes in nonstructural carbohydrates, protein, and macronutrients in roots of alfalfa, red clover, sweetclover, and birdsfoot trefoil.," Crop Science, vol. 36, June. 1996, pp. 617-623.

[9] S. Kaur, R. M. Vohra, M. Kapoor, Q. K. Beg and G. S. Hoondal, "Enhanced production and characterization of a highly thermostable alkaline protease from bacillus sp. p-2.," World Journal of Microbiology and Biotechnology, vol. 17, Feb. 2001, pp. 125-129.

[10] M. Shabeb, and M. Younis, "Production of Cellulase in Low-cost Medium by Bacillus Subtilis KO Strain," World Applied Sciences Journal, vol. 8, Jan. 2010, pp. 35-42.

[11] J. F. Li, S. Q. Zhang, S. L. Shi, and P. H. Huo, "Ventilation conditions on phosphorus dissolving Rhizobia" Grassland and Turf, vol. 30, Jan. 2010, pp. 28-32. 